\title{
Analysis of aflatoxin B1 and aflatoxigenic mold in commercial poultry feeds in Tamil Nadu, India
}

\author{
Y. Sireesha ${ }^{1}$, J. Vimal Keerthana ${ }^{1}$, G. Sarathchandra ${ }^{2}$ and R. Velazhahan ${ }^{{ }^{*}}$ \\ ${ }^{1}$ Department of Plant Pathology, Tamil Nadu Agricultural University, Coimbatore-641003(Tamil Nadu), INDIA \\ ${ }^{2}$ Pharmacovigilance Laboratory for Animal Feed and Food Safety, Centre for Animal Health Studies, Chennai- \\ 600051 (Tamil Nadu), INDIA \\ Veterinary and Animal Sciences University, Chennai-600051 (Tamil Nadu), INDIA \\ *Corresponding author. E-mail: velazhahan@hotmail.com
}

Received: July 19, 2016; Revised received: November 17, 2016; Accepted: February 14, 2017

Abstract: A total of 48 commercial poultry feed samples collected from different poultry feed manufactures in Tamil Nadu, India were examined for the contamination of aflatoxin B1 (AFB1) and Aspergillus flavus. AFB1 in the samples was estimated by sandwich ELISA and the presence of $A$. flavus was detected by Real-Time PCR assay. Real-Time PCR analysis using $A$. flavus- specific omt primers confirmed the presence of $A$. flavus in all the samples tested. ELISA results indicated that the AFB1 contents in the poultry feeds ranged from 1.0 to18.7 ppb, which were below the permissible safe limits for poultry bird consumption and health. The results suggest adoption of good manufacturing practices by the commercial poultry feed manufacturers during procurement of feed ingredients, handling, storage and processing which might have suppressed the growth of $A$. flavus and aflatoxin contamination.

Keywords: Aflatoxin, Aspergillus flavus, ELISA, Molecular detection, PCR

\section{INTRODUCTION}

Maize (Zea mays L.) is one of the most important cereal crops worldwide and contributes to food security in most of the developing countries (Ranum et al., 2014). In India, maize is emerging as the third most important crop after rice and wheat. It accounts for approximately 9 per cent of total food grain production in the country. Approximately $50 \%$ of total production goes for feed use, primarily for poultry feed. Aflatoxin contamination of maize kernels is one of the major problems worldwide. These aflatoxins are a group of structurally related polyketide-derived secondary metabolites produced by certain strains of Aspergillus flavus Link ex Fries and Aspergillus parasiticus Speare. These aflatoxins are acutely toxic, carcinogenic, mutagenic, teratogenic and immunosuppressive compounds. Common aflatoxins are aflatoxin B1 (AFB1), B2 (AFB2), G1 (AFG1) and G2 (AFG2). AFB1 is the most potent of all aflatoxins (Lee et al., 2004). This toxin is the most potent carcinogen found in nature (Castegnaro and McGregor, 1998).

Although maize is infected by different species of Aspergillus in the field, A. flavus is the dominating aflatoxin-producing fungus especially in tropical regions (Calvert et al., 1978, Setamou et al., 1997). The fungus grows well when the temperature is between $18^{\circ} \mathrm{C}$ and $33^{\circ} \mathrm{C}$ and the relative humidity is greater than 50 per cent. The prevailing weather conditions in India favor the growth of the fungus and subsequently the production of aflatoxin in kernels. Aflatoxin contamination of maize may occur at any stage before and after harvest and during drying, storage and processing. When contaminated maize kernels are used as ingredient for poultry feed, potentially harmful amounts of aflatoxin may be ingested by poultry birds. Some of the metabolites formed during the metabolism of AFB1 are transmitted to edible animal products viz., liver, muscle (Bintvihok and Davitiyananda, 2002) and eggs, which exert toxic, immunosuppressive and teratogenic effects on human beings. In order to prevent entry of aflatoxin in food chain, most developed countries have set stringent regulatory requirements on the level of aflatoxins permitted in imported and traded commodities (Van Egmond, 1989). In the United States, for example, the Food and Drug Administration (FDA) has established an action level for total aflatoxins in human food at 20 parts per billion (ppb) (Park and Liang, 1993).

Aflatoxin contamination in poultry feeds causes significant economic losses to poultry industries (Awad et al., 2006). Consumption of such aflatoxin contaminated feed results in a disease called aflatoxicosis in poultry. An outbreak of aflatoxicosis in commercial poultry farms was reported in the Chittoor district of Andhra Pradesh state, India with $100 \%$ mortality (Choudary and Rao, 1982). It has been reported that each $\mathrm{mg}$ of AFB $1 / \mathrm{kg}$ feed would decrease the growth performance of broilers by $5 \%$ (Dersjant-Li et al., 
2003). Raju and Devegowda (2000) recorded 21\% decrease in body weight at 35 days age in broilers fed with $0.3 \mathrm{mg}$ AFB1 $/ \mathrm{kg}$ feed. Al-Shawabkeh et al. (2009) reported that feeds contaminated with aflatoxin B1 caused a significant increase in feed conversion ratios, a decrease in body gain and a significant increase in feed consumption in broiler chickens. Furthermore, the nutritional value of poultry meat (combined breast, thigh and respective skin) in terms of CLA contents was affected by the concentration of AFB1 added to the feed. The level and length of AFB1 exposure affect the amount of reduction in weight gain of broilers (Yunus et al., 2011). The aim of present study was to quantify AFB1 in poultry feeds from commercial poultry feed manufacturers by sandwich ELISA and detection of A. flavus by Real-Time PCR assay.

\section{MATERIALS AND METHODS}

Sample collection: Forty eight poultry feed samples were collected from commercial feed manufacturers in Tamil Nadu, India. The presence of AFB1 in naturally contaminated poultry feed samples was detected by sandwich ELISA as described by Kannan and Velazhahan (2015).

Extraction of aflatoxins from poultry feeds: Powdered feed samples $(50 \mathrm{~g})$ were macerated with $250 \mathrm{ml}$ of methanol: water $(55: 45 \mathrm{v} / \mathrm{v}), 100 \mathrm{ml}$ of hexane and $2 \mathrm{~g}$ of sodium chloride. The extract was filtered; methanolic layer was separated and then extracted with $25 \mathrm{ml}$ of chloroform thrice. The chloroform fractions were pooled and evaporated to dry in vacuo. The residue was dissolved in $0.05 \mathrm{M}$ carbonate buffer $(\mathrm{pH} 9.6)$ and used as antigen.

Sandwich ELISA: The wells of microtiter plates (Genaxy Scientific PVT LTD, Solan, India) were coated with $150 \mu \mathrm{l} /$ well of antiserum raised against AFB1-KLH in carbonate coating buffer $(0.05 \mathrm{M}$ carbonate buffer, $\mathrm{pH}$ 9.6) (1: 10,000 dilution) and incubated at $4^{\circ} \mathrm{C}$ overnight. The plates were washed thrice with phosphate buffered saline (PBS) containing $0.05 \%$ Tween-20 (PBST). AFB1 standard/sample extract $(150 \mu \mathrm{l})$ was added into the coated wells and incubated for $2 \mathrm{~h}$ at $37^{\circ} \mathrm{C}$. The plates were washed thrice with PBST and $150 \mu \mathrm{l} /$ well of antiserum raised against AFB1-KLH in $0.05 \mathrm{M}$ carbonate coating buffer was added into each well. After incubation for $2 \mathrm{~h}$ at $37^{\circ} \mathrm{C}$, $150 \mu \mathrm{l}$ of alkaline phosphatase -labelled goat antirabbit IgG (Genei, Merck Specialities P. Ltd. Mumbai, India) at 1:4,000 dilution in carbonate buffer was applied. The plates were incubated at $37^{\circ} \mathrm{C}$ for $2 \mathrm{~h}$ and then washed with PBST for 5 times and $150 \mu \mathrm{l}$ of freshly prepared $p$-nitrophenyl phosphate $(0.5 \mathrm{mg} / \mathrm{ml})$ in $10 \%$ diethanolamine ( $\mathrm{pH} 9.8)$ was added to each well. The microtiter plates were incubated for approximately $30 \mathrm{~min}$ and read at $405 \mathrm{~nm}$ on a microtiter plate reader (Sunrise ${ }^{\mathrm{TM}}$, Tecan groups Ltd, Switzerland).
Detection of A. flavus by real-time PCR assay: In order to detect the presence of A. flavus in poultry feeds, Real-time PCR assay was conducted as described by Shweta et al. (2013). Approximately 100 $\mathrm{mg}$ of feed samples were ground to a powder in liquid nitrogen and the DNA was extracted by using the CTAB extraction method (Doyle and Doyle, 1987). Real-time PCR amplification was performed using Light Cycler 480 SYBR Green Master mix (Roche

Table 1. Detection of aflatoxin B1 in poultry feed samples by ELISA.

\begin{tabular}{|c|c|c|}
\hline S.No. & $\begin{array}{l}\begin{array}{l}\text { Poultry feed samples } \\
\text { (Sample code) }\end{array} \\
\end{array}$ & $\begin{array}{c}\text { AFB1 Concentration } \\
(\mathbf{p p b})\end{array}$ \\
\hline 1 & 1786 & 7.7 \\
\hline 2 & 3055 & 6.7 \\
\hline 3 & $3033-3034$ & 9.2 \\
\hline 4 & 176-177 & 5.6 \\
\hline 5 & 2132 & 6.4 \\
\hline 6 & 704-705 & 5.2 \\
\hline 7 & 3089 & 7.5 \\
\hline 8 & $97 \mathrm{~A}$ & 5.4 \\
\hline 9 & 2831 & 6.0 \\
\hline 10 & 2830 & 6.5 \\
\hline 11 & 1778 (629 A) & 5.8 \\
\hline 12 & G 1 & 6.9 \\
\hline 13 & $2817-2818$ & 4.1 \\
\hline 14 & $753-755$ & 3.2 \\
\hline 15 & $261-262$ & 5.3 \\
\hline 16 & $627 \mathrm{~A}$ & 2.5 \\
\hline 17 & $717-720$ & 3.1 \\
\hline 18 & $741-743$ & 5.2 \\
\hline 19 & 2129 & 18.7 \\
\hline 20 & 341 & 6.8 \\
\hline 21 & $2704-2706$ & 8.2 \\
\hline 22 & $2130 \mathrm{G}$ & 6.2 \\
\hline 23 & $652-654$ & 8.5 \\
\hline 24 & $655-657$ & 6.3 \\
\hline 25 & $747-749$ & 8.4 \\
\hline 26 & 795 (2724) & 5.1 \\
\hline 27 & $2891-2892(1779)$ & 8.4 \\
\hline 28 & $758-760$ & 3.4 \\
\hline 29 & $2703-2706$ & 6.1 \\
\hline 30 & $644-645(1860)$ & 4.8 \\
\hline 31 & $869-870$ & 4.6 \\
\hline 32 & 1898 & 5.6 \\
\hline 33 & $3091 \mathrm{~A}$ & 6.7 \\
\hline 34 & $1941 \mathrm{G}$ & 5.7 \\
\hline 35 & $1879(782-783)$ & 4.6 \\
\hline 36 & $744-746$ & 2.1 \\
\hline 37 & $750-752$ & 6.6 \\
\hline 38 & $649-651$ & 2.0 \\
\hline 39 & $1788(9-100)$ & 1.4 \\
\hline 40 & $2133 \mathrm{G}$ & 2.9 \\
\hline 41 & $658-660$ & 1.0 \\
\hline 42 & $1938 \mathrm{G}$ & 9.9 \\
\hline 43 & 796-797(1891) & 1.3 \\
\hline 44 & 1868 & 9.9 \\
\hline 45 & $2707-2708$ & 1.9 \\
\hline 46 & $646-648$ & 1.6 \\
\hline 47 & $761-763$ & 1.2 \\
\hline 48 & $\mathrm{C} 1$ & 1.2 \\
\hline
\end{tabular}




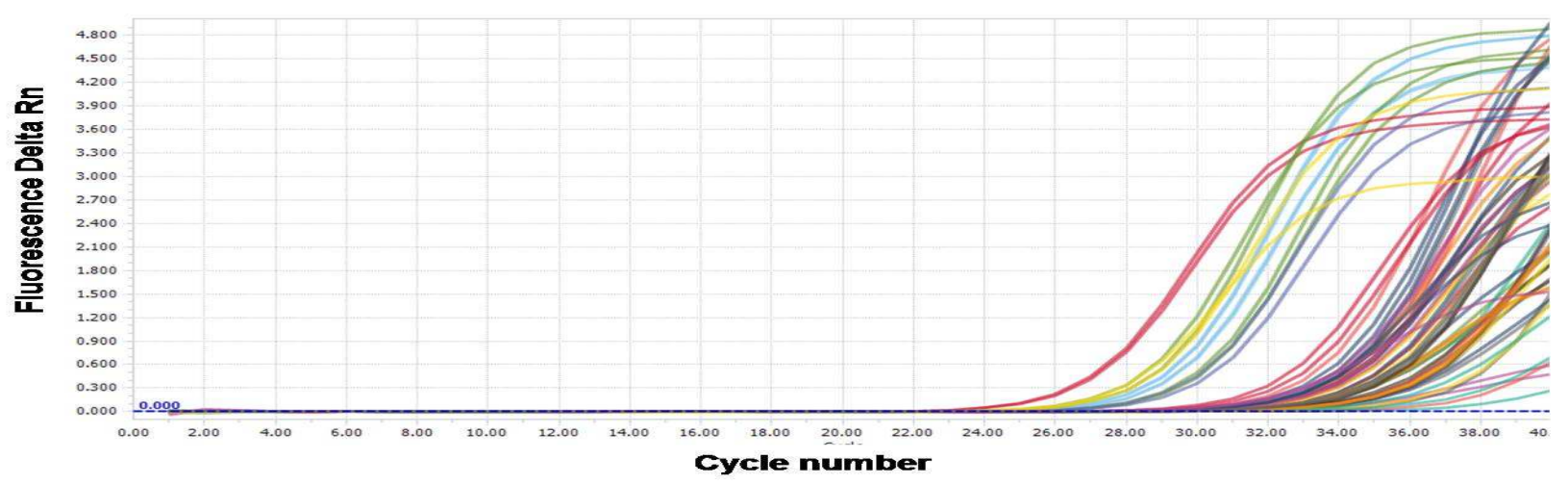

Fig. 1. Amplification curves on the detection of A. flavus through Real-Time PCR using SYBR Green, indicating the increase of the fluorescence signal in DNA obtained from naturally infected poultry feed samples.

Diagnostics GmbH, Manheim, Germany) and Roche Light Cycler 96 (Roche Diagnostics GmbH, Manheim, Germany). The PCR reaction contained $5 \mu \mathrm{l}$ of $2 \mathrm{X}$ Light Cycler 480 SYBR Green Master mix, 5 pmol each of omt forward (5' GACCAATACGCCCACACAG-3') and reverse (5' CTTTGGTAGCTGTTTCTCGC -3') primers and $5 \mathrm{ng}$ of DNA template in a final volume of $10 \mu \mathrm{l}$. Thermal cycling conditions consisted of initial denaturation for $7 \mathrm{~min}$ at $95{ }^{\circ} \mathrm{C}$, followed by 35

Table 2. Real-time PCR assays in poultry feed samples.

\begin{tabular}{|c|c|c|}
\hline S.No. & Sample ID & Ct value \\
\hline 1 & 1786 & 32.46 \\
\hline 2 & $176-177$ & 34.55 \\
\hline 3 & 704-705 & 31.54 \\
\hline 4 & 3089 & 34.79 \\
\hline 5 & $97 \mathrm{~A}$ & 34.05 \\
\hline 6 & 2831 & 36.42 \\
\hline 7 & 2830 & 34.98 \\
\hline 8 & $1778(629 \mathrm{~A})$ & 33.47 \\
\hline 9 & G 1 & 33.12 \\
\hline 10 & $2817-2818$ & 33.59 \\
\hline 11 & $753-755$ & 34.78 \\
\hline 12 & $261-262$ & 32.34 \\
\hline 13 & $627 \mathrm{~A}$ & 32.63 \\
\hline 14 & $717-720$ & 29.07 \\
\hline 15 & $741-743$ & 33.12 \\
\hline 16 & 2129 & 34.82 \\
\hline 17 & 341 & 34.10 \\
\hline 18 & $2130 \mathrm{G}$ & 33.93 \\
\hline 19 & $652-654$ & 27.49 \\
\hline 20 & $655-657$ & 28.31 \\
\hline 21 & $747-749$ & 35.80 \\
\hline 22 & $2891-2892(1779)$ & 34.83 \\
\hline 23 & $2703-2706$ & 32.77 \\
\hline 24 & $3091 \mathrm{~A}$ & 28.95 \\
\hline 25 & $1941 \mathrm{G}$ & 34.11 \\
\hline 26 & $1879(782-783)$ & 25.97 \\
\hline 27 & $744-746$ & 33.15 \\
\hline 28 & $750-752$ & 35.09 \\
\hline 29 & $649-651$ & 27.54 \\
\hline 30 & $1788(9-100)$ & 35.45 \\
\hline 31 & $658-660$ & 36.63 \\
\hline 32 & 796-797(1891) & 33.37 \\
\hline 33 & $2707-2708$ & 36.35 \\
\hline 34 & $\mathrm{C} 1$ & 28.02 \\
\hline
\end{tabular}

cycles of $95^{\circ} \mathrm{C}$ for $30 \mathrm{~s}$, annealing temperature of $59^{\circ} \mathrm{C}$ for $30 \mathrm{~s}$ and extension at $72^{\circ} \mathrm{C}$ for $30 \mathrm{~s}$. After the PCR cycle, a melting curve of the product was generated by ramping the temperature to $95^{\circ} \mathrm{C}$ for $10 \mathrm{~s}$, back to $65^{\circ}$ $\mathrm{C}$ for $60 \mathrm{~s}$, and then incremental increases of $4.4^{\circ} \mathrm{C} / \mathrm{s}$ up to $95^{\circ} \mathrm{C}$ with continuous measurement of fluorescence. The threshold cycle $(\mathrm{Ct})$ value for each reaction was assessed using the Light Cycler 96 S W 1.0 software (Roche Diagnostics GmbH, Manheim, Germany).

\section{RESULTS AND DISCUSSION}

As shown in Table 1, AFB1 was detected in all the feed samples analyzed and the AFB1 content in the naturally contaminated poultry feeds ranged from 1.0 to18.7 ppb. However, the quantities were below the permissible limit for poultry bird consumption and health. When these naturally contaminated poultry feed samples were analyzed for the presence of $A$. flavus by conventional PCR using omt primers, the expected 300-bp product was amplified in most of the AFB1 contaminated feed samples (Data not shown). However, some of the feed samples even though contain AFB1 failed to amplify the 300-bp product in conventional PCR. The same samples showed positive results when analyzed by Real-time PCR (Fig. 1). The intercalating dye, SYBR Green showed satisfactory results in the detection of $A$. flavus in poultry feeds. The Ct values ranged from 19.61 to 26.11 for $7.3 \times 10^{11}$ to $7.3 \times 10^{7}$ copies, respectively, of the target DNA se-

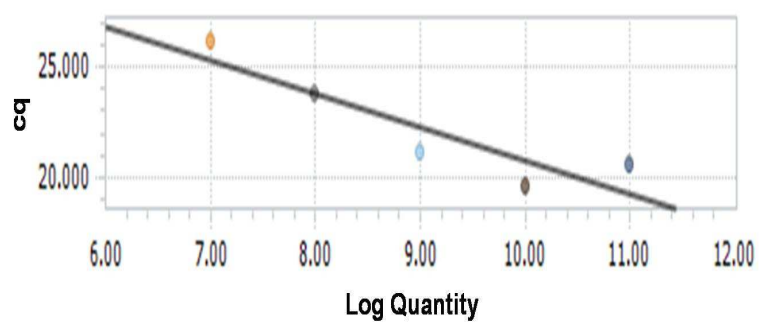

Fig. 2. Real-time PCR standard curve of the log of amount of A. flavus DNA, versus the corresponding cycle quantitative (Cq) values. 


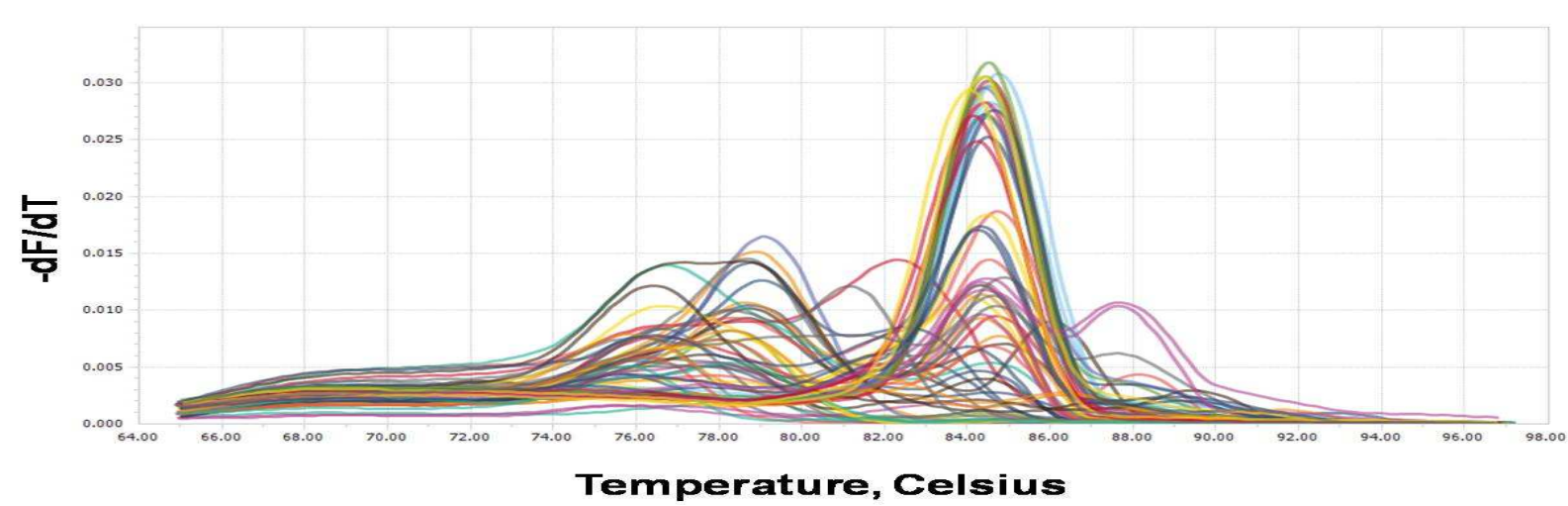

Fig. 3. Melting curve for the target amplicon of A. flavus in naturally infected poultry feed samples as analyzed by Real-Time PCR.

quence (Fig. 2). The Ct values were between 25.97 and 36.63 (Table 2) for the naturally infected poultry feed samples and confirmed the presence of the fungus in the samples. The $\mathrm{R}^{2}$ value of 0.93 in standard curve strongly supports the reliability of the results. The melting curve analysis showed a major peak with a melting point of $84^{\circ} \mathrm{C}$ (Fig.3). The RT-PCR assay is reproducible between replicate samples. The evaluation of the Real-time PCR products, obtained from the amplification of DNA fragments of naturally contaminated poultry feed samples with omt primers designed for A. flavus, through electrophoretic analysis in $1.0 \%$ agarose gel generated bands of $300 \mathrm{bp}$ (Data not shown), indicating specificity of the primers.

Bhat et al. (1997) reported that $26 \%$ of maize kernels collected from different parts of India were contaminated with AFB1 beyond the level of Indian standard for consumption $(30 \mu \mathrm{g} / \mathrm{kg})$. Waliyar et al. (2003) reported that $43 \%$ of maize samples collected from retail shops or super markets in Hyderabad, Andhra Pradesh, India were contaminated with toxin with the highest AFB1 level of $806 \mu \mathrm{g} / \mathrm{kg}$. Using RT-PCR technique, Shweta et al. (2013) proved the presence of A. flavus in maize kernel samples. Vijayasamundeeswari et al. (2009) reported that $58 \%$ of the maize kernel samples collected from different agro-ecological zones of Tamil Nadu, India was contaminated with AFB 1 and the levels of AFB 1 in $26 \%$ of the pre- and post-harvest maize kernels exceeded $20 \mu \mathrm{g} \mathrm{kg}{ }^{-1}$. Kannan et al. (2014) reported that $98 \%$ of the poultry feed samples collected from poultry farms and poultry feed dealers of Tamil Nadu, India were contaminated with AFB1 and the levels ranged from 0 to $160.7 \mathrm{ppb}$ and the levels of AFB1 in $29 \%$ of the samples exceeded 20 ppb. Kannan and Velazhahan (2015) reported that AFB 1 contamination was found in more than $88 \%$ of the poultry feeds samples collected from Tamil Nadu, India and its level ranged from 5.4 to $125.4 \mu \mathrm{g} / \mathrm{kg}$.

The presence of aflatoxins in agricultural commodities poses a serious health threat to both humans and domestic animals. Several studies reported the presence of residual aflatoxins in liver and meat of broilers when fed with aflatoxin contaminated feeds (Oliveira et al., 2000; Hussain et al., 2010; Herzallah, 2013). In the case of laying hens, aflatoxins and their metabolites were detected in the eggs (Trucksess et al., 1983). The results of this study indicate that the AFB1 content in the poultry feeds were below the tolerance level fixed by the FAO for poultry bird consumption suggesting adoption of good manufacturing practices by the feed manufacturers during the procurement of feed ingredients, handling, storage and processing of feeds to ensure the safety of feeds for poultry consumption. The amplification of target DNA fragment might be due to the indiscriminate detection by PCR independent of the viability status of the fungus. Novel PCRbased strategy, propidium monoazide - Real-Time quantitative PCR, that differentiate nucleic acids associated with viable cells from those associated with inactivated cells has to be tested (Nocker and Camper, 2009; Crespo-Sempere et al., 2013; Cangelosi and Meschke, 2014).

\section{Conclusion}

It could be concluded that $A$. flavus was detected in all poultry feed samples tested by Real-time PCR. However, the poultry feeds were contaminated with low levels of aflatoxin B1 (1.0 -18.7 ppb), suggesting adoption of good manufacturing practices by the feed manufacturers during the procurement of feed ingredients, handling, storage and processing of feeds to ensure the safety of feeds for poultry consumption. The amplification of target DNA fragment in PCR might be due to the indiscriminate amplification by PCR independent of the viability status of the fungus. It is necessary to increase the awareness among farmers and traders about the importance of aflatoxins and to adopt improved management practices to minimize aflatoxin contamination in feed ingredients.

\section{ACKNOWLEDGEMENTS}

This study was supported by the Department of Science and Technology, Government of India, New Delhi. 


\section{REFERENCES}

Al-Shawabkeh, K., Herzallah, S., Al-Fataftah, A. and Zakaria, H. (2009). Effect of Aflatoxin B1 contaminated feed on broiler chickens performance and meat content of conjugated linoleic acid. Jordan J. Agric. Sci., 5: 314 $-322$

Awad, W. A., Bohm, J., Razzazi-Fazeli, E., Faukal, K. and Zentek, J. (2006). Effect of addition of a probiotic microorganism to broiler diets contaminated with deoxynivalenol on performance and histological alterations of intestinal villi of broiler chickens. Poult. Sci., 85: 974979

Bhat, R.V., Vasanthi, S., Rao, B.S., Rao, R.N., Rao, V.S., Nagaraja, K.V., Bai, R.G., Prasad, C.A., Vanchinathan, S., Ray, R., Saha, S., Mukherjee, A., Ghosh, P.K., Toteja, G.S. and Saxena, B.W. (1997). Aflatoxin B1 contamination in maize samples collected from different geographical regions of India - a multicentre study. Food Addit Contam., 14:151-156.

Bintvihok, A. and Davitiyananda, D. (2002). Aflatoxins and their metabolite residues in chicken tissues from 5 parts (10 provinces) of Thailand. Thai J. Hlth. Res., 16:37-50.

Calvert, O. H., Lillehoj, E. B., Kwolek, W. F. and Zuber, M. S. (1978). Aflatoxin $B_{1}$ and $G_{1}$ production in developing Zea mays kernels from mixed inocula of Aspergillus flavus and A. parasiticus. Phytopathology, 68:501-506.

Cangelosi, G.A. and Meschke, J.S. (2014). Dead or Alive: Molecular assessment of microbial viability. Appl. Environ. Microbiol., 80: 5884-5891.

Castegnaro, M. and McGregor, D. (1998). Carcinogenic risk assessment of mycotoxins. Rev. Med. Vet. 149:671-678.

Choudary, C. and Rao, M. R. K. M. (1982). An outbreak of aflatoxicosis in commercial poultry farms. Poultry Adviser, 16:75-76

Crespo-Sempere, A., Estiarte, N., Marín, S., Sanchis, V. and Ramos, A. J. (2013). Propidium monoazide combined with real-time quantitative PCR to quantify viable Alternaria spp. contamination in tomato products. Int. J. Food Microbiol., 165: 214-220.

Dersjant-Li, Y., Verstegen, M.W.A. and Gerrits, W.J.J. (2003). The impact of low concentrations of aflatoxin, deoxynivalenol or fumonisin in diets on growing pigs and poultry. Nutr. Res. Rev., 16: 223-239

Doyle, J.J. and Doyle, J.L. (1987). A rapid DNA isolation procedure for small quantities of fresh leaf tissue. Phytochem. Bull., 19:11-15

Herzallah, S. M. (2013). Aflatoxin B1 residues in eggs and flesh of laying hens fed aflatoxin B1 contaminated diet. Am. J. Agric. Biol. Sci., 8: 156-161

Hussain, Z., Khan, M.Z., Khan, A., Javed, I., Saleemi, M.K., Mahmood, S. and Asi, M.R. (2010). Residues of aflatoxin B1 in broiler meat: Effect of age and dietary aflatoxin B1 levels. Food Chem. Toxicol., 48:3304-3307

Kannan, K. and Velazhahan, R. (2015). Detection of aflatoxin $\mathrm{B} 1$ contamination in foods and feeds by enzymelinked immunosorbent assay. Biochem. Cell. Arch., 15: 509-513

Kannan, K., Supriya, S., Adhithya, R. and Velazhahan, R.
(2014). Aspergillus flavus and aflatoxin contamination of poultry feeds in Tamil Nadu, India. Int. J. Agric. Environ. \& Biotechnol., 7: 293-298

Lee, N.A., Wang, S., Allan, R.D. and Kennedy, I.R. (2004). A rapid aflatoxin B1 ELISA: Development and validation with reduced matrix effects for peanuts, corn, pistachio, and soybeans. J. Agric. Food Chem., 52:27462755

Nocker, A. and Camper, A.K. (2009). Novel approaches toward preferential detection of viable cells using nucleic acid amplification techniques. FEMS Microbiol. Lett., 291: 137-142

Oliveira, C.A.F., Kobashigawa, E.W., Reis, T.A., Mestieri, L., Albuquerque, R. and Correa, B. (2000). Aflatoxin $\mathrm{B} 1$ residues in eggs of laying hens fed a diet containing different levels of the mycotoxins. Food Addit. Contam., 17:459-462

Park, D. L. and Liang, B. (1993). Perspectives on aflatoxin control for human food and animal feed. Trends Food Sci. Technol., 4:334-342

Raju, M.V.L.N. and Devegowda, G. (2000). Influence of esterified-glucomannan on performance and organ morphology, serum biochemistry and haematology in broilers exposed to individual and combined mycotoxicosis (aflatoxin, ochratoxin and T-2 toxin). Br. Poult. Sci., 41:640-650

Ranum, P., Pena-Rosas, J. and Garcia-Casal, M. (2014). Global maize production, utilization, and consumption. Ann. N Y Acad. Sci.,1312:105-112

Setamou, M., Cardwell, K. F., Schulthess, F. and Hell, K. (1997). Aspergillus flavus infection and aflatoxin contamination of preharvest maize in Benin. Plant Dis., 81: 1323-1327

Shweta, S., Madhavan, S., Paranidharan, V. and Velazhahan, R. (2013). Detection of Aspergillus flavus in maize kernels by conventional and real-time PCR assays. Int. Food Res. J., 20: 3329-3335

Trucksess, M.W., Stoloff, L., Young, K.Y., Wyatt, R.D. and Miller, B.L. (1983). Aflatoxicol and aflatoxins B1 and M1 in eggs and tissues of laying hens consuming aflatoxin contaminated feed. Poult. Sci., 62:2176-2182

Van Egmond, H.P. (1989). Current situation on regulations for mycotoxins. Overview of tolerances and status of standard methods of sampling and analysis. Food Addit Contam., 6:139-188

Vijayasamundeeswari, A., Mohankumar, M., Karthikeyan, M., Vijayanandraj, S., Paranidharan, V. and Velazhahan, R. (2009). Prevalence of aflatoxin B1 contamination in pre- and post-harvest maize kernels, food products, poultry and livestock feeds in Tamil Nadu, India. J. Plant Prot. Res., 49: 221-224

Waliyar, F., Reddy, S.V., Subramaniam, K., Reddy, T.Y., Ramadevi, K., Craufurd, P.Q. and Wheeler, T.R. (2003). Importance of mycotoxins in food and feed in India. Asp. Appl. Biol., 68: 147-154

Yunus, A. W., Razzazi-Fazeli, E. and Bohm, J. (2011). Aflatoxin B1 is affecting broiler's performance, immunity, and gastrointestinal tract: A review of history and contemporary issues. Toxins, 3:566-590 